\title{
Makapuno Coconut: A Potential New Commercial Source of Galactomannan
}

\author{
Maria Judith B. Rodriguez, $\mathrm{PhD}^{1}$
}

\begin{abstract}
Novel uses of Makapuno mutant coconut were explored. The focus was on the endosperm, which is rich in galactomannan as compared with that of the normal coconut. Galactomannan, also referred to as gum, is a non-starch polysaccharide that can vary in physicochemical properties depending on the plant source. The galactomannans available in the market are imported and sourced mostly from temperate leguminous plants.

An inexpensive, large-scale method of isolating galactomannan from waste Makapuno liquid endosperm was developed. The powder produced could be classified into different grades according to purity, fineness, color and whether it is food-grade or not. It has the functional properties of a thickener, binder, extender, gelling agent, emulsifier and stabilizer.

To showcase the use of Makapuno galactomannan as a plant-based biopolymer and a hydrocolloid material, several formulations were tried and tested to come up with products such as biodegradable or edible film, jelly, hand and body lotion, and even electrophoresis gel. However, they have to be further improved in terms of quality, shelf life and safety for commercialization to be considered. Other prospective applications of Makapuno galactomannan are discussed.
\end{abstract}

Keywords: bio-polymer, endosperm, galactomannan, gum, hydrocolloid, Makapuno, polysaccharide

${ }^{1}$ Philippine Coconut Authority-Albay Research Center, Banao, Guinobatan, Albay 4503, Philippines. 


\section{Introduction}

Makapuno nut, a mutant coconut, is produced on palms along with normal nuts. As it does not germinate, its production in the Philippines is being accelerated through an improved embryo culture technology (Rillo et al., 2002). Alongside increasing production, new products that can penetrate both the local and export markets have to be developed for the Makapuno industry to thrive. The soft Makapuno solid endosperm cannot be made into copra. Traditionally, it is made into jam, candies and as flavoring for ice cream.

Studies have shown that carbohydrate metabolism is a major point of difference between Makapuno and normal coconut (Mendoza et al., 1989 and Flavier et al., 1996 as cited by Ramirez and Mendoza, 1998). Fractionation of the polysaccharides revealed that Makapuno endosperm contains 2 to 8 times more water-soluble galactomannan than normal coconut endosperm (Samonte et al., 1987 as cited by Ramirez and Mendoza, 1998). Watersoluble galactomannan accumulates in the maturing Makapuno while its level in the maturing normal coconut decreases with a parallel increase in the water-insoluble mannan. The deficiency in $\alpha$-D-galactosidase permits the accumulation of galactomannan in Makapuno while its high activity in the normal coconut results in an increase in mannan (Mujer et al., 1984 and Samonte et al., 1993 as cited by Ramirez and Mendoza, 1998). The galactomannan makes the Makapuno solid endosperm soft, fluffy and gelatinous, and makes the liquid endosperm highly viscous. On the other hand, the large amount of mannan makes the mature normal solid endosperm hard and compact.

Galactomannan is a reserve polysaccharide consisting of a linear chain of mannose residues with galactose as a side group. It can vary in physicochemical properties as determined by the degree of polymerization, branching of the polymers and the mannose-galactose $(\mathrm{M} / \mathrm{G})$ ratio (Mulimani and Prashanth, 2002). The rich sources are members of the family Leguminoseae. Galactomannan is also referred to as gum (or mucilage) because of its ability to form viscous solutions with water, or as hydrocolloid, since it is present in seeds in a dissolved or highly hydrated colloidal state (Meyer, 1964). Vegetable gum and hydrocolloid can be found in the listing of ingredients in various food/cosmetic/pharmaceutical products indicating a wide-ranging commercial application for galactomannan.

As to the galactomannan from Makapuno, its large-scale isolation, utilization and commercialization have not been explored yet. The endosperm of split Makapuno nut spoils easily through microbial action within a day, so the need to isolate and purify the galactomannan is imperative. Hence, the objectives of this study are to develop an economically feasible Makapuno galactomannan production technology and to showcase value-added products.

\section{Methodology}

A trial on isolating galactomannan according to the procedures of Buckeridge $e t$ al. (1995) and Kapoor (1972) was first conducted. Mature Makapuno nuts (tagged as 11 months and 2 weeks old) were harvested. The endosperm was defatted by washing twice with acetone $(1: 1 \mathrm{w} / \mathrm{v})$. The defatted endosperm was suspended in hot distilled water, stirred properly and kept on a rotary shaker at $160 \mathrm{rpm}$ for $5 \mathrm{hr}$. The suspension was passed through muslin cloth. The residue was used for the second extraction of the polysaccharide. To the filtrate, $10 \%$ trichloroacetic acid was added in a 1:1 ratio to precipitate protein. The solution was centrifuged at 15,000 rpm for $30 \mathrm{~min}$. To the supernatant, 4 volumes of chilled absolute ethanol were added to precipitate galactomannan. The solution was centrifuged at $15,000 \mathrm{rpm}$ for $30 \mathrm{~min}$. The supernatant was discarded and the precipitate containing the fibrous galactomannan was washed with ethanol/ether and dried.

Based on the outcome of the above trial, a method of isolating galactomannan applicable to the industrial production of this compound was devised. To showcase its potentials, some valueadded products were developed. 


\section{Results and discussions}

\section{Production of galactomannan from waste Makapuno liquid endosperm}

Using the combined procedures of Buckeridge et al. (1995) and Kapoor (1972), more galactomannan could be extracted from the solid endosperm (or meat) than from the liquid endosperm. However, it was more laborious and costly to use the meat as the raw material aside from the fact that it can be used for other purposes. Usually, the meat is made into confectioneries while the liquid endosperm is just thrown away. It is, therefore, economically viable to extract galactomannan from the waste liquid endosperm.

The presence of other compounds such as lipids and proteins was found to be negligible in the liquid endosperm. This further facilitated the development of a quick and inexpensive process of isolating galactomannan applicable to the commercial production of this compound with comparable efficiency to that of Buckeridge et $a l$. and Kapoor (Figure1).

The production scheme entailed collecting the liquid endosperm from newly harvested Makapuno nuts under hygienic conditions. The raw material was either processed immediately or stored at $5^{\circ} \mathrm{C}$ to $-20^{\circ} \mathrm{C}$. Basically, the process necessitated filtration, precipitation and centrifugation to separate and concentrate the galactomannan fraction. The end product was in powder form and could be classified into different grades according to purity, fineness, color and whether it is food-grade or not. The yield and quality were found to be dependent on the \% alcohol content of the extraction solvent. The higher the alcohol content, the higher the yield and the more pure, white and powdery the final product had become and consequently, the longer the shelf life. For food-grade galactomannan, edible organic solvents that are locally available such as gin and distilled coconut toddy or lambanog were used to replace the expensive imported chemicals.

To compensate for the high production cost of galactomannan with the Makapuno solid endosperm as raw material, a study is in progress with the aim of developing a process that will at the same time recover the other functional components of the meat such as lipids and proteins. Besides galactomannan, the other fractionated compounds can also be made into valuable products that include virgin coconut oil (VCO) and protein-based formulations.

Another study is on-going, which is in relation to the three types of Makapuno (I, II and III). They are distinguished by the degree of softness and thickness of the solid endosperm or by whether it fills the whole cavity of the nut. Makapuno type I is the typical one with the entire cavity of the shell fully filled with the soft, jelly-like meat. It is easy to identify among the harvested nuts, as it has almost no liquid endosperm that makes a splashing sound when a mature nut is shaken. Type II has viscous liquid endosperm but not as much as that of type III. Type I with the softest solid endosperm is preferred for making ball candies since it is easily shredded and molded into balls, whereas type III with its hard endosperm shredded into strips is preferred for making chunky jams. Preliminary findings indicated that the galactomannans from the three types of Makapuno differ in physicochemical properties suggesting the need to segregate the nut harvest or identify the source palm from one type to the other as they may require different applications.

Luno (or Lono), another type of mutant coconut in the Philippines that was reported by Menon and Pandalai (1958) to have a soft and sweet endosperm not suited for making copra, is also being studied for its functional components and innovative utilization.

\section{Development of value-added products from Makapuno galactomannan}

In powder form, Makapuno galactomannan (Figure 2) can be a natural ingredient for food product formulations. It has the functional properties of a thickener, binder, extender, gelling agent, emulsifier (mixes water and oil) and stabilizer (maintains state of oil dispersion).

Plant proteins, lipids, resins or polysaccharides can be made into biodegradable and edible coatings and films used to extend the 
Cord 2010, 26 (2)

Figure 1. Large-scale production of Makapuno galactomannan from waste liquid endosperm

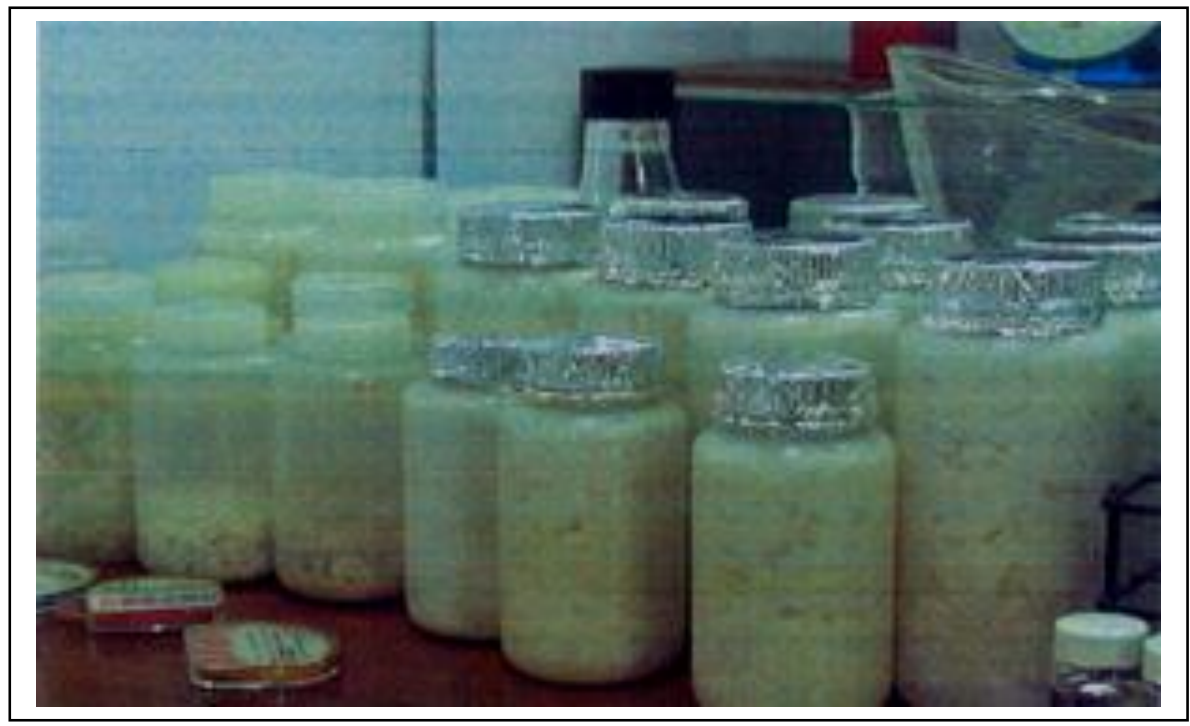

Figure 2. Makapuno galactomannan powder

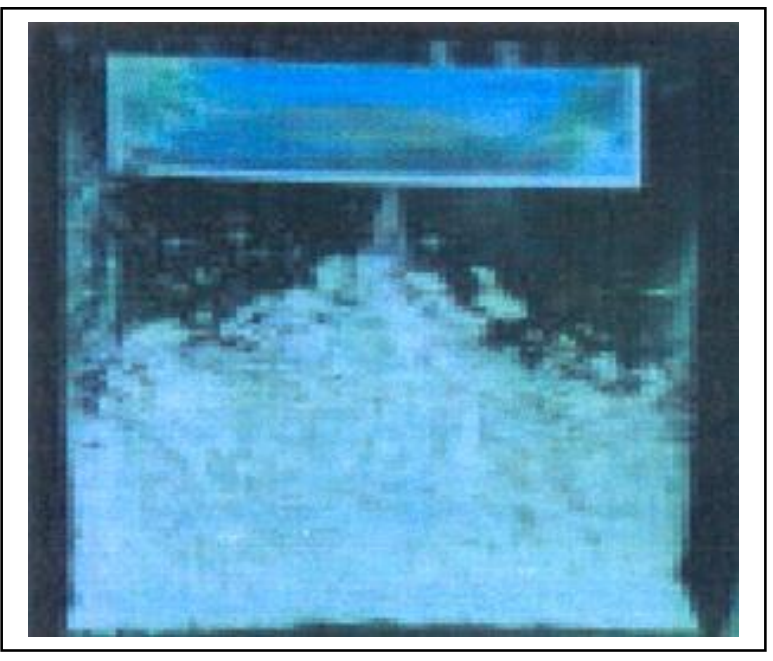

Figure 3. Makapuno galactomannan biofilm

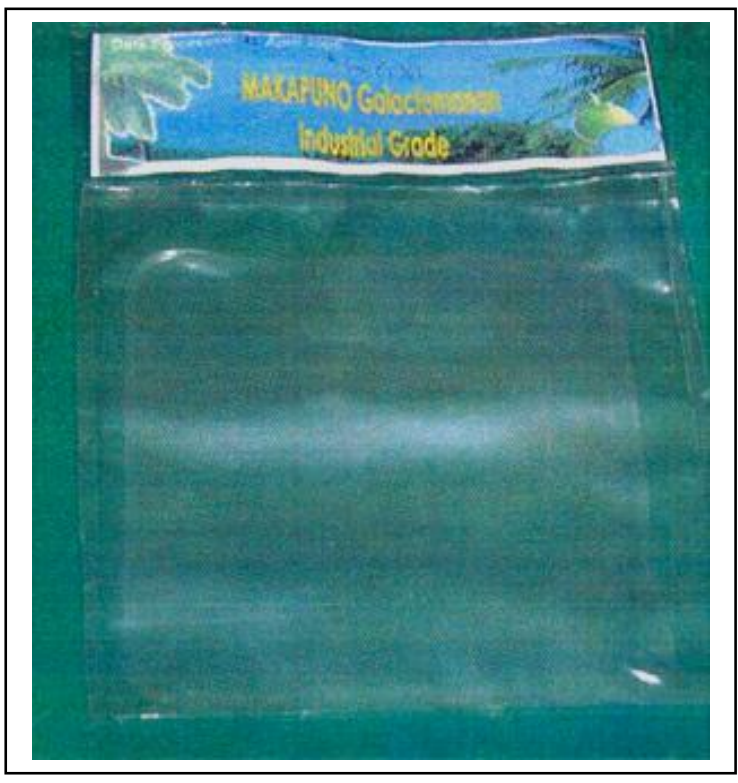


shelf life of fresh produce while improving its overall nutritional value. The food is either wrapped in a dry film or sprayed with a liquid that dries into a protective coating. Because they are edible, they can be prepared and eaten with the food, leaving nothing to remove or throw away. A biodegradable film or biofilm (Figure 3) was produced after experimenting on different proportions of Makapuno galactomannan. This was tried as wrapping for candies, fresh spring roll and other food preparations.

With the growth of vegetarianism, there is an increasing demand for plant-based products as alternatives for gelatin. Gelatin is made from boiled bones, skins and tendons of animals. Carrageenan is currently replacing gelatin in the market (Figure 4).

Newly harvested Makapuno liquid endosperm, when applied to the hands and other parts of the body including hair, has a soothing and moisturizing effect. This is because of the galactomannan content, which is a biopolymer with natural hydrating function. With its high moisturizing capacity, it can be considered as a component of cosmetic products that treat dry, damaged or aged skin as well as products that help to improve the physical properties of hair. A hand and body lotion was formulated with Makapuno galctomannan as the major ingredient. Upon testing, it was found to be nongreasy and no allergic reaction was observed.

Agarose and polyacrylamide are both very expensive to use as a sieving matrix for electrophoresis. Because of its physicochemical properties, Makapuno galactomannan can be substituted for, or combined with, agarose or polyacrylamide. Phenol extraction of endogenous proteins according to Dolnik et al. (2001) was done to obtain a relatively pure Makapuno galactomannan. This was tried in the preparation of electrophoresis gels for coconut DNA fingerprinting and Cadang-cadang viroid indexing, as the use of cheaper chemicals can generate savings. These laboratory tests are done routinely at the Philippine Coconut AuthorityAlbay Research Center.

There are other prospective applications of Makapuno galactomannan that have not been investigated yet. Being a non-starch carbohydrate, specifically a water-soluble polysaccharide, it can be a dietary fiber food supplement. In a drug delivery system, active ingredients can be entrapped in the hydrocolloid matrix of Makapuno galactomannan. The complexes formed impart a new possibility of providing essential metal ions in dietary foods as decomplexation can occur at different $\mathrm{pH}$ values existing in the human body (Merce et al., 2001). With or without a pharmaceutically active agent, a gum-borate composition can be administered to the eye for lubrication or to supplement tears in the treatment of dry eyes. Makapuno galactomannan can be used as thickener in toothpastes, as the binder in tablets, as a soft gel capsule for active ingredients dissolved in oil and as an alternative absorbent material for sanitary napkin, disposable diaper, etc. There is a high demand now for stable, biodegradable wound dressing materials that can absorb body fluids, deliver medications to keep wounds clean and speed up the healing process. The Makapuno galactomannan biofilm may have the properties that suit these requirements.

Makapuno galactomannan as an alternative to industrial polymers that serve as binders, thickeners, emulsifiers and stabilizers can have applications in the textile, paper, explosives, oil well drilling and mining industries. Chemical modification of pure Makapuno galactomannan to introduce new functional groups of the polysaccharide molecule can also be explored. This can create derivatives with novel physicochemical properties tailored to specific needs (Dolnik et al., 2001)

\section{Mak gum: a new gum in the market}

For a more appropriate trade name, Makapuno galactomannan is herein shortened to Mak gum. Table 1 presents the types of galactomannan in the market as against Mak gum (Samonte et al., 1987; Mulimani and Prashanth, 2002). They are listed in the order of increasing mannose to galactose or $\mathrm{M} / \mathrm{G}$ ratio. Mannose is hydrophobic while galactose is hydrophilic. Hence, the lesser the rate of galactose becomes, the lesser the solubility of the galactomannan. 


\begin{tabular}{|c|c|c|c|c|}
\hline \multicolumn{5}{|c|}{ Table 1. Types of galactomannan } \\
\hline Trade name & Plant source & Place grown & M/G ratio & Solubility \\
\hline Fenugreek gum & $\begin{array}{l}\text { Trigonella } \\
\text { foenumgraecum } \mathrm{L} .\end{array}$ & $\begin{array}{l}\text { Southern part of } \\
\text { Canada; } \\
\text { Mediterranean region }\end{array}$ & $1: 1$ & $\begin{array}{l}\text { Extremely water- } \\
\text { soluble }\end{array}$ \\
\hline Guar gum & $\begin{array}{l}\text { Cyamopsis } \\
\text { tetragonoloba }\end{array}$ & $\begin{array}{l}\text { Indian subcontinent; } \\
\text { some parts of Texas } \\
\text { and Oklahoma }\end{array}$ & $2: 1$ & Cold water-soluble \\
\hline $\begin{array}{l}\text { Tara gum or } \\
\text { Huarango or } \\
\text { Peruvian carob }\end{array}$ & $\begin{array}{l}\text { Caesalpinia } \\
\text { spinosa }\end{array}$ & South America & $3: 1$ & $\begin{array}{l}\text { Water-soluble at } \\
\text { ambient temperature }\end{array}$ \\
\hline Mak gum & $\begin{array}{l}\text { Cocos nucifera } \mathrm{L} \\
\text { (Makapuno) }\end{array}$ & Philippines & $3: 1$ & $\begin{array}{l}\text { Water-soluble at } \\
\text { ambient temperature }\end{array}$ \\
\hline $\begin{array}{l}\text { Locust bean } \\
\text { gum or Carob } \\
\text { gum or Carubin }\end{array}$ & Ceretonia siliqua & Africa & $4: 1$ & $\begin{array}{l}\text { Water-soluble at } \\
85^{\circ} \mathrm{C}\end{array}$ \\
\hline
\end{tabular}

Figure 4. Makapuno jelly

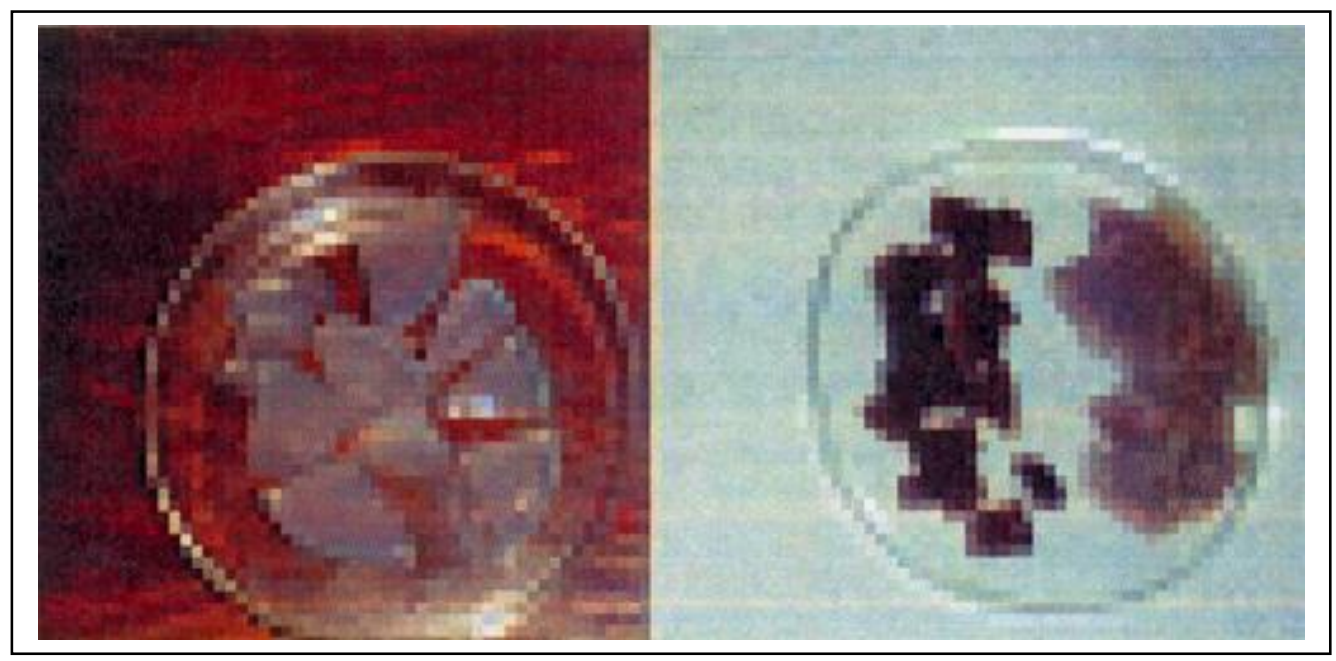


Guar gum has the highest usage in foods, mainly due to its low and stable price. Guar and Locust bean gum are commonly used in making ice cream to improve texture and reduce ice cream meltdown. Locust bean gum is also used extensively in cream cheese, fruit preparations and salad dressings. Tara gum as a food ingredient is still used to a much lesser extent than Guar or Locust bean gum. Fenugreek gum is considered as a medicinal natural food additive. Since it has a high ratio of galactose, it has apparently a strong effect of lowering the level of sugar and cholesterol in the blood. Because it is a dietary fiber, it can also cause weight loss. As to Mak gum, this is the first report on its production and potential for commercialization.

\section{Recommendations}

It was demonstrated that Makapuno mutant coconut could be a new commercial source of galactomannan with an $\mathrm{M} / \mathrm{G}$ ratio of 3:1. Mak gum is the suggested trade name. The waste liquid endosperm is the economically viable starting material. As it is a potential new gum in the market with a wide range of application, funding and an industry partnership are needed for its commercialization, including marketing and promotion. R\&D should likewise be continued to maximize the production and utilization of galactomannan and other functional compounds from the Makapuno solid endosperm.

\section{Acknowledgment}

The author would like to thank the management of the Philippine Coconut Authority-Albay Research Center for providing the start-up research fund, the Tissue Culture Division for supplying the Makapuno nuts and Ms. Susan N. Operio for assisting in the laboratory works.

\section{References}

Buckeridge, M.S., Panegassi, V.R., Rocha, D.C. and Dietrich, S.M.C. 1995. Seed galactomannan in the classification and evolution of Leguminoseae. Phytochemistry 38: 871-875

Dolnik, V., Gurske, W.A. and Padua, A. 2001. Galactomannans as a sieving matrix in capillary electrophoresis. Electrophoresis 22: 707-719

Kapoor, V.P. 1972. A galactomannan from the seeds of Delonix regia. Phytochemistry 11: 1129-1132

Menon, K.P.V. and Pandalai, K.M. 1958. The Coconut Palm: A Monograph, Indian Central Coconut Committee, India

Merce, A.L.R., Fernandes, E., Mangrich, A.S., Sierakowski, M.R. and Szpoganicz, B. 2001. Fe(III)-galactomannan solid and aqueous complexes: Potentiometric, EPR, spectroscopy and thermal data. J. Braz. Chem. Soc. 12(6)

Meyer, L.H. 1964. Food Chemistry. Reinhold Publishing Corporation, New York

Mulimani, V.H. and Prashanth, S.J. 2002. Investigating plant galactomannans. Biochemistry and Molecular Biology Education 30(2): 101-103

Ramirez, D.A. and Mendoza. E.M.T. (1998). The Makapuno Mutant Coconut. The National Academy of Science and Technology, Philippines

Rillo, E.P., Cueto, C.A., Medes, W.R. and Areza-Ubaldo, M.B. 2002. Development of an improved embryo culture protocol for coconut in the Philippines. In Coconut Embryo In-Vitro Culture: Part II, F. Engelmann, P. Batugal and J.T. Oliver, editors, IPGRI-APO, Serdang, Malaysia 